\title{
Dynamic loading of the tank container on a flat wagon considering fittings displacement relating to the stops
}

\author{
Oleksij Fomin ${ }^{1}$, Juraj Gerlici ${ }^{2}$, Alyona Lovskaya ${ }^{3}$, Mykola Gorbunov $^{4}$, Kateryna Kravchenko ,*, $^{*}$ \\ Pavlo Prokopenko ${ }^{5}$, and Tomas Lack ${ }^{2}$
}

\begin{abstract}
${ }^{1}$ State University of Infrastructure and Technology, Department of Cars and Carriage Facilities, 9 Kyrylivska str., 04071 Kyiv, Ukraine ${ }^{2}$ University of Zilina, Department of transport and handling machines, Univerzitná 8215/1, 01026 Zilina, Slovak Republic ${ }^{3}$ Ukrainian State University of Railway Transport, Department of Wagons, 7 Feuerbach Square 7, 61050 Kharkov, Ukraine ${ }^{4}$ Volodymyr Dahl East Ukrainian National University, Department of railway, road transport and handling machines, 59a Central Avenue, 93400 Sewerodonetsk, Ukraine

${ }^{5}$ Branch "Research and Design and Technological Institute of Railway Transport", PJSC "Ukrzaliznytsya", 39 Ivana Fedorova, 03038 Kyiv, Ukraine
\end{abstract}

\begin{abstract}
The mathematical modelling of the dynamic loading of the container-tank during maneuvering collision of the flat wagon has made it possible to obtain an accurate value of the accelerations acting on its supporting structure. At the same time, possible movements of the tank-container relative to the frame of the flat wagons due to the presence of a technological gap in the pair "fitting stop-fitting" are taken into account. It is established that this acceleration, which is a component of the dynamic load, exceeds the one permitted by the regulatory documents. A computer simulation of the dynamic loading of the tank container in the CosmosWorks software environment was also carried out. The calculation was carried out using the finite element method. The results of the simulation made it possible to determine the distribution fields of the accelerations acting on the supporting structure of the tank-container during the shunting of the flat wagon, as well as their numerical values. Checking the adequacy of the mathematical and computer models using the Fisher criterion allowed us to conclude that the hypothesis of adequacy is not rejected.
\end{abstract}

\section{Introduction}

Ensuring the effectiveness of the developing economic ties between the states of Europe and Asia calls for the introduction of combined transport operations. To date, one of the most promising vehicles that have found application in combined transport is a container, and for the carriage of fluid cargo - a container-tank.

The increase in the volume of fluid cargo transportations towards the international transport corridors foreshows an increase in the level of demand for container-cisterns. In connection with this, there is a need to develop and put into operation new tank-containers with improved technical and economic indicators [1-5].

\section{Analysis of recent research and publications}

A study of the dynamic loads acting on the tank-container placed on the flat wagon during the manoeuvring collision is presented in [6].

The determination of the accelerations acting on the tank-container was carried out taking into account the gaps between the fitting stops of the flat wagon and the fittings of the tank-container. The longitudinal force acting on the flat wagon from the wagon-striker was about
$2200-2800 \mathrm{kN}$, depending on the capacity of the tankcontainer.

The studies were carried out on tank containers for transportation of gasoline and nitric acid with a gross mass of 21.9 tons and 24.0 tons, respectively.

It is important to note that the maximum value of the longitudinal impact force, which can act on the flat wagon with the cargo placed on it, including the tank containers, with a shunting collision, is $3.5 \mathrm{MN}[7,8]$. Therefore, in order to obtain an accurate value of the accelerations acting on the container-tank in operation, additional studies are needed.

A study of the strength of tank-container model TK25 and the optimization of its supporting structure are given in $[9,10]$. When compiling the model of the strength of the tank-container, the normative values of the loads given in [11] are taken into account.

A study of the strength of the load-bearing structure of the tank-container, taking into account the specified operational values of the loads (the compliance of the fluid cargo, the movement of fittings relative to the fitting stops, etc.) is not carried out.

In works $[12,13]$, the feasibility of designing and commissioning tank containers as vehicles has been justified, the results of optimizing the design of tank containers are given. Advanced designs of tank containers for transportation of oil products have been developed.

\footnotetext{
* Corresponding author: kkatherina@ukr.net
} 
The structural features of tank-containers for transportation of liquefied gases are discussed in [14]. The material of the supporting structure of the container is stainless steel. To limit the thermal impact of the environment on the container, it is proposed to encapsulate it with an insulating system.

Features of computer modelling of the supporting structure of a tank-container are given in [15]. The finite element method is used as the calculation method.

A study of the transfer of heat flow through the internal supports of cylindrical vessels using the example of a tank-container was considered in [16]. The paper simulates the heat flow through a multilayer support made of plastic.

Tests of metal and composite containers under the impact of low temperatures are given in [17]. It determines what types of containers it is expedient to use for transportation of the specified nomenclature of cargoes taking into account low ambient temperature.

Questions about the creation of ideal load-bearing structures of railway vehicles and the requirements that they must meet at the current stage of development are covered in [18-20].

The aforementioned works, studies of the dynamic loading of tank containers by methods of mathematical and computer modelling, taking into account possible displacements relative to the flat wagon frame, did not pay attention to the shunting collision.

\section{Exposition of the object of research}

An analysis of the regulatory documents on the issues of ensuring the strength of tank containers in operation allowed us to conclude that the greatest values of the dynamic loads acting on their load-bearing structures and fastening devices are indicated in [11].

It is agreed that the construction of the tank-container must withstand the inertia forces arising during the movement of the vehicle, as well as during the shunting of the wagons, including during the dissolution from the hills, emergency braking in trains at low speeds, with the following accelerations: in the longitudinal direction $P_{l}-$ $2 g$; in the transverse direction $P_{t}-1 g$; in the vertical direction $P_{v}-2 \mathrm{~g}$; at impact: for the loaded container $-4 g$; for empty container (for the purpose of checking the fittings) $-5 g$.

To determine the operational values of the dynamic loads acting on the supporting structure of the tankcontainer placed on the flat wagon during manoeuvring collision, the mathematical model given in [6] was used. This model takes into account that three tank containers are placed on a long-based flat wagon, and the connection between them was simulated as an elastic-friction one, that is, each tank-container has its own degree of freedom in the vertical plane (formulas: 1-7).

The components of a mathematical model are determined by the formulas (8-11).

It is important to note that in the transportation of tankcontainers, flat wagons on the frame of which two containers can be accommodated are also used. Such wagons have a smaller base, and accordingly less than the amount of movement of the supporting structure under the influence of the vertical load from the containers [21].

Therefore, in this study, research was conducted on the 13-4085flat wagon model, the construction of JSC Dniprovagonmash and the TK25tank-container model, built JSC Zarechensky Chemical Mechanical Engineering Factory. The tank-container is of ISO-1CC standard size and is intended for transportation of fuels and lubricants, gasoline, diesel fuel, engine oil, oil, oil solvents, nefras, foaming agents.

The tank-container was considered as an attached mass in relation to the flat wagon frame, having longdistance compliance due to the presence of gaps between the fitting stops of the flat wagon and the container-tank fittings. That is, the tank-container has its own degree of freedom up to the moment of fitting in the fitting stop, after which the container-tank repeats the trajectory of moving the flat wagon (Fig. 1).

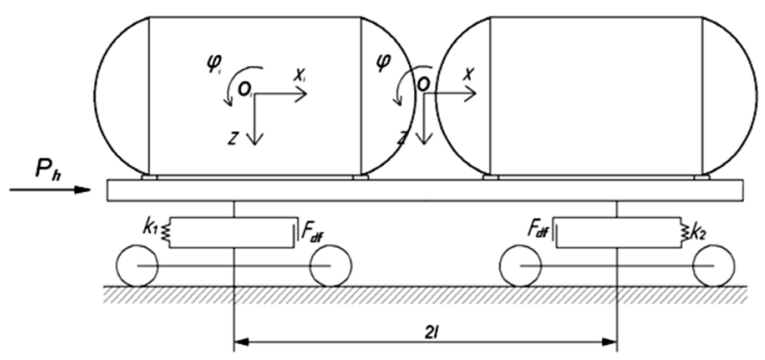

Fig. 1. Scheme of action of the longitudinal force on the flat wagon with the tank-containers placed on it.

The connection between the frame of the flat wagon and the container-tank fittings was simulated as frictional. At the same time, it is taken into account that the tankcontainers placed on the flat wagon have the same boiler workload of the fluid cargo.

$$
\begin{aligned}
& M_{f w}^{\prime} \ddot{x}_{f w}+M_{f w} h \ddot{\varphi}_{f w}=S_{c}-\sum_{i=1}^{2} S_{i}, \\
& I_{f w} \ddot{\varphi}_{f w}+M_{f w} h \ddot{x}_{f w}-g \varphi_{f w} M_{f w} h= \\
& l F_{d f}\left(s n g \dot{\Delta}_{1}-s n g \dot{\Delta}_{2}\right)+l\left(k_{1} \Delta_{1}-k_{2} \Delta_{2}\right), \\
& M_{f w} \ddot{z}_{f w}=k_{1} \Delta_{1}+k_{2} \Delta_{2}-F_{d f}\left(s n g \dot{\Delta}_{1}-s n g \dot{\Delta}_{2}\right), \\
& \left(m_{i}+\sum_{j=1}^{k} m_{i j}\right)\left(\ddot{x}_{f w}+\ddot{x}_{i}\right)+\left(m_{i} z_{c i}+\sum_{j=1}^{k} m_{i j} c_{i j}\right) \times \\
& \left(\ddot{\varphi}_{f w}-\ddot{\varphi}_{i}\right)-\sum_{j=1}^{k} m_{i j} l_{i j} \ddot{\xi}_{i j}=S_{i} \\
& \left(I_{\theta i}+\sum_{j=1}^{k} m_{i j} c_{i j}^{2}\right)\left(\ddot{\varphi}_{f w}-\ddot{\varphi}_{i}\right)+ \\
& \left(m_{i} z_{i}+\sum_{j=1}^{k} m_{i j} c_{i j}\right)\left(\ddot{x}_{f w}+\ddot{x}_{i}\right)+\sum_{j=1}^{k} m_{i j} c_{i j} l_{i j} \ddot{\xi}_{i j}- \\
& g\left(m_{i} z_{i}+\sum_{j=1}^{k} m_{i j} c_{i j}\right)\left(\varphi_{f w}-\varphi_{i}\right)=0 \\
& \left(m_{i}+\sum_{j=1}^{k} m_{i j}\right) \ddot{z}_{f w}=0, \\
& I_{i j} \ddot{\xi}_{f w}-m_{i j} l_{i j} \ddot{x}_{i j}-m_{i j} c_{i j} l_{i j} \ddot{\varphi}_{i j}+g m_{i j} l_{i j} \ddot{\xi}_{i j}=0,
\end{aligned}
$$

where

$$
\begin{gathered}
M_{f w}^{\prime}=M_{f w}+2 m_{b}+\frac{n I}{r^{2}} \\
\Delta_{1}=z_{f w}-l \varphi_{f w} ; \\
\Delta_{2}=z_{f w}+l \varphi_{f w} ; \\
S_{i}=f_{d f} \operatorname{sng}\left(x_{f w}-x_{i}\right)^{\prime},
\end{gathered}
$$


$M_{f w}$ - weight of the supporting structure of the flat wagon, $\mathrm{t} ; I_{f w}-$ moment of inertia of the flat wagon with respect to the longitudinal axis, $\mathrm{t} \cdot \mathrm{m}^{2} ; S_{c}-$ magnitude of the longitudinal impact force in the coupler, $\mathrm{kN} ; F_{d f}-$ amplitude value of the dry friction force, $\mathrm{kN} ; m_{b}$ - weight of the bogie, $\mathrm{t} ; I$ - moment of inertia of the wheel pair, $\mathrm{t} \cdot \mathrm{m}^{2} ; r$-radius of the medium-worn wheel, $\mathrm{m} ; n$-number of axles of the bogie; $l$ - half the base of the flat wagon, $\mathrm{m} ; F_{d f}-$ the absolute value of the dry friction force in the spring set, $\mathrm{kN} ; k_{1}, k_{2}$ - rigidity of springs spring suspension of carriages of the flat wagon, $\mathrm{kN} / \mathrm{m} ; k-$ number of tones of fluctuations in fluid cargo; $m_{i}-$ mass of the body equivalent to the $i$-th tank-container with a part of the fluid cargo that does not participate in the movement relative to the boiler, $\mathrm{t} ; m_{i j}$ - mass of the $j$-th pendulum in the $i$-th container-cistern, $\mathrm{t} ; z_{c i}$ - height of the center of gravity of the tank-container, $\mathrm{m} ; c_{i j}-$ distance from the plane to the point of fixation of the $j$-th pendulum in the $i$-th container-tank; $l_{i j}-$ length of the $j$-th pendulum, $\mathrm{m} ; I_{\theta}-$ the given moment of inertia of the $i$-th tank-container and the fluid cargo, not taking part in the movement relative to the boiler, $\mathrm{t} \cdot \mathrm{m}^{2} ; I_{i j}$ - moment of inertia of the pendulum, $\mathrm{t} \cdot \mathrm{m}^{2} ; x, y, z-$ coordinates corresponding, respectively, longitudinal, angular around the longitudinal axis and vertical displacement of the flat wagon; $x_{i}, \varphi_{i}$ - coordinates corresponding, respectively, longitudinal and angular around the longitudinal axis to the displacement of the tank-container; $\ddot{\xi}_{i j}-$ angle of deviation of the $j$-th pendulum from the vertical.

In this case $x_{i}<30 \mathrm{~mm}[6,22]$, if $x_{i} \geq 30 \mathrm{~mm}$, then $x_{i}=x$.

Vertical movements of the tank-container relative to the flat wagon frame were not taken into account. The compliance of the fluid cargo with respect to the walls of the tank-container cistern was also taken into account. The movement of fluid cargo was described by a set of mathematical pendulums [6]. The force of the longitudinal impact acting on the wagon frame is taken to be $3.5 \mathrm{MN}$.

Determination of the hydrodynamic characteristics of fluid cargo was carried out according to the procedure given in [23]. Petrol was assumed to be the bulk cargo, On the basis of the calculations carried out in the case of the maximum permissible workload of the tank-container boiler, in accordance with [24], the value of $m_{i j} \approx 6.8 \mathrm{t}$, $I_{i j} \approx 250 \mathrm{t} \cdot \mathrm{m}^{2}$, was obtained.

The solution of the differential equations was carried out using the Runge-Kutta method in MathCad software environment $[25,26]$.

The results of the studies made it possible to conclude that the maximum accelerations that act on the tankcontainer are about $300 \mathrm{~m} / \mathrm{s}^{2}$.

Also, a study of the dynamic loading of a tankcontainer was carried out using computer simulation in CosmosWorks software environment, version 2015 [27]. A spatial model of the load-bearing structure of a flat wagon with containers is shown in Fig. 2.

The calculation was carried out using the finite element method. When compiling the finite element model, spatial isoparametric tetrahedra are used. The number of grid nodes was 707359, the elements -
2150500. The maximum element size was $50 \mathrm{~mm}$, the minimum $-10 \mathrm{~mm}$. The minimum number of elements in the circle was 9 , the ratio of the increase in the dimensions of the elements in the grid is 1.7. The maximum aspect ratio is 689.01 , the percentage of elements with aspect ratio of less than $3-52.1$, more than $10-4.75$.

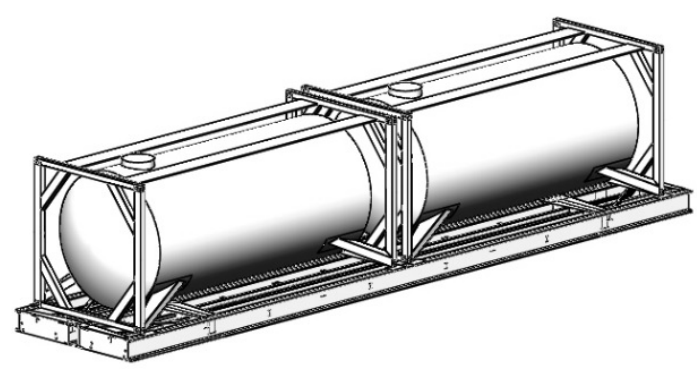

Fig. 2. Spatial model of the flat wagon with tank containers placed on it.

When compiling the strength model (Fig. 3), it is taken into account that, apart from the longitudinal force $P_{h}, \mathrm{kN}$, there are vertical forces acting on the flat wagon in the container support areas on the fitting stops. The container has a vertical response in the fitting area of the fitting to the fitting stop, the internal pressure of the fluid cargo $P_{f c}$, $\mathrm{kPa}$ on the boiler, the longitudinal load $P_{l l}, \mathrm{kN}$ on the bottom of the boiler when the fluid cargo moves, due to the action of the longitudinal force $P_{h}$ on the rear stop of the coupler and the movement of the fittings relative to the fitting stops by the amount of the technological gap. To account for the frictional force in the areas of interaction between the flat wagon and the containers, the modal damping coefficient was used.

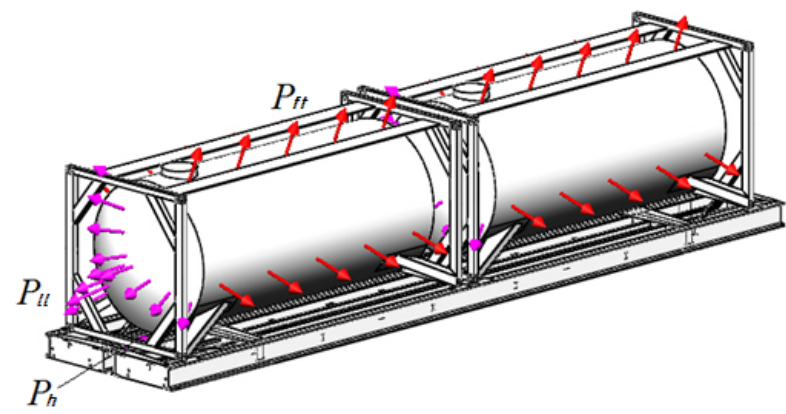

Fig. 3. The model of the strength of the flat wagon with tank containers placed on it under the action of longitudinal force on the rear stop of the automatic coupler.

The fixing of the model was carried out in the areas of supporting the supporting structure on the running gear. As the material for the load-carrying structure of the flat wagons and containers, steel 09G2C was used with a tensile strength value of $490 \mathrm{MPa}$ and a yield strength of $345 \mathrm{MPa}[7,8]$.

The results of the computer simulation are shown in Fig. 4.

From the studies, which were carried out, it can be concluded that the maximum acceleration acting on the tank-container was about $320 \mathrm{~m} / \mathrm{s}^{2}$.

To check the adequacy of the developed model, Fisher's criterion was used. 


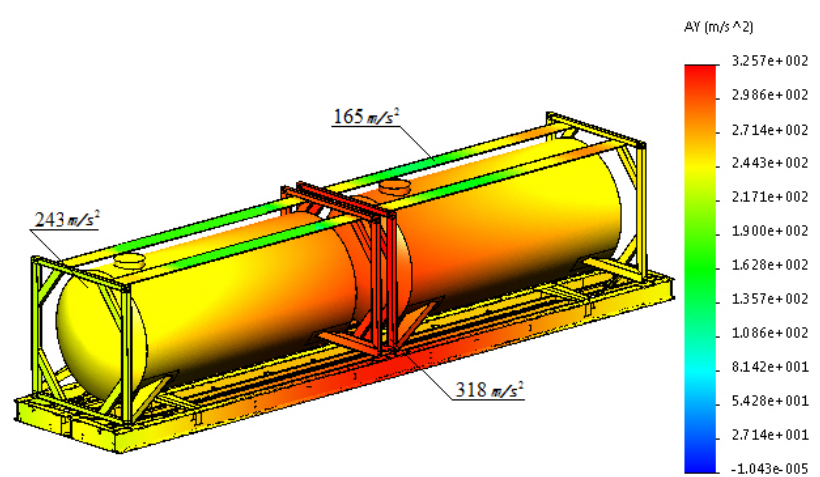

Fig. 4. Acceleration of the flat wagon with the containers placed on it when the longitudinal force acts on the rear stop of the automatic coupler.

It was established that the considered model is linear and characterizes the change in the acceleration of the tank-container placed on the flat wagon from the longitudinal force acting on the rear fence of the automatic coupler. In this case, the number of degrees of freedom for $N=6$ will be $f=4$.

On the basis of the calculations, it has been established that the actual value of criterion $F_{c l}=1.6$ is less than the table value of criterion $F_{t}=6.16$. Consequently, the hypothesis of adequacy is not rejected.

The obtained results for the accelerations, as components of the dynamic load, are taken into account in the study of the strength of the load-bearing structure of the tank-container. The results of the calculations made it possible to conclude that the maximum equivalent stresses in the construction of a tank container arise in the zone of interaction between the boiler support and the fitting stop and are about $1015 \mathrm{MPa}$ (Fig. 5), the maximum displacements in the structural units were $13.6 \mathrm{~mm}$, the deformations $-6.08 \times 10^{3}$ [21] .

The distribution of stresses along the length of the lower transverse belt of the tank-container frame is shown in Fig. 6. It can be seen from the figure that the maximum equivalent stresses are concentrated in the areas of placement of the container-tank fittings, and they decrease towards the central part of the belt.

\section{Conclusion}

The conducted research allowed us to define the specified value of acceleration, which acts on the supporting structure of the tank-container taking into account the movements of the fittings relative to the fitting stops of the flat wagon. Calculation of the strength showed that with possible movements of the tank container relative to the platform car frame in the conditions of the shunting collision and the underload of the boiler with the fluid load, the stresses in the load-bearing structure exceed the permissible ones. The results of the research will contribute to the creation of a new-generation tankcontainers with improved technical and economic parameters that will improve the efficiency of the transport process towards international transport corridors.

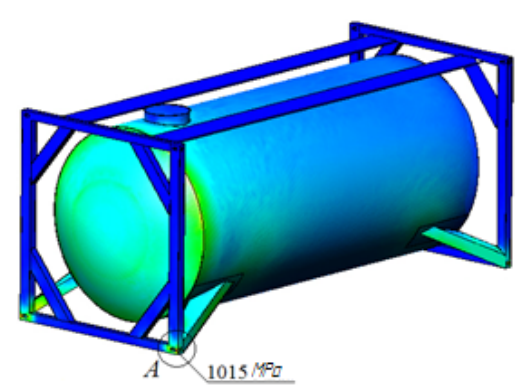

A (increased):

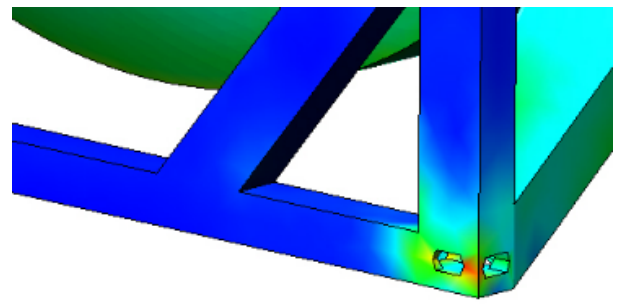

Fig. 5. Results of the calculation of the strength of the loadbearing structure of the tank-container TK25.

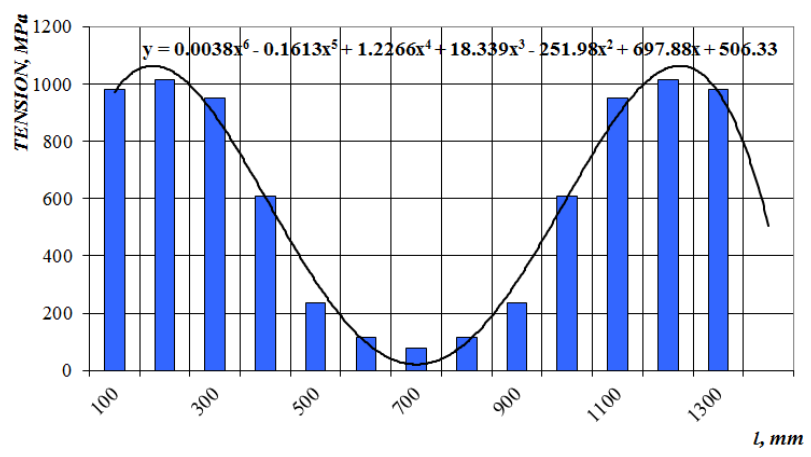

Fig. 6. Distribution of stresses along the length of the lower transverse belt of the tank-container frame.

\section{References}

1. P. Fabian, J. Gerlici, J. Masek, P. Marton, Versatile, efficient and long wagon for intermodal transport in Europe, Komunikacie, 15(2), 118-123 (2013)

2. J. Dižo, J. Harušinec, M. Blatnický, Computation of modal properties of two types of freight wagon bogie frames using the finite element method, Manufacturing Technology, 18(2), 208-214 (2018)

3. I. Gritsuk, Y. Gutarevych, V. Mateichyk, V. Volkov, Improving the processes of preheating and heating after the vehicular engine start by using heating system with phase-transitional thermal accumulator, SAE Technical Paper 2016-01-0204 (2016), https://doi.org/10.4271/2016-01-0204

4. V. Hauser, O. Nozhenko, K. Kravchenko, M. Loulová, J. Gerlici, T. Lack, Car body and bogie connection modification for track curves passability improvement, 22nd Slovak-Polish Scientific Conference on Machine Modelling and Simulations, MMS 2017, Sklene Teplice, Slovakia, MATEC Web of Conferences, 157 (5-8 September 2017) 
5. P. Štastniak, M. Moravčík, Freight bogie prototype properties analysis by means of simulation computations, Manufacturing Technology, 17(3), 381-388 (2017)

6. G. Bogomaz, D. Mehov, O. Pilipchenko, Y. Chernomashentseva, Load of tank containers located on a railway platform, when striking a coupler (in Russian), Collection of scientific works "Dynamics and control of movement of mechanical systems", Kiev, 87-95 (1992)

7. Norms for the calculation and design of railroad wagons of the Ministry of Railways of gauge 1520 $\mathrm{mm}$ (non-self-propelled) (in Russian), Moscow: GosNIIV, VNIIZhT, 319 (1996)

8. GOST 33211. Freight wagons. Requirements for strength and dynamic qualities (in Russian). Moscow: Standartinform, 54 (2016)

9. O. Fomin, O. Burlutsky, Y. Fomina, Development and application of cataloging in structural design of freight car building, Scientific and technical journal "Metallurgical and Mining Industry", 2, 250-256 (2015)

10. O. Fomin, A. Lovskaya, A. Plakhtiy, V. Nerubatsky, The influence of implementation of circular pipes in load-bearing structures of bodies of freight cars on their physico-mechanical properties, Scientific Bulletin of National Mining University, 6(162), 89-96 (2017)

11. GOST 31232. Containers for the transport of dangerous goods. Requirements for operational safety (in Russian), Belarusian State Institute for Standardization and Certification, Minsk, 6 (2005)

12. S. Myamlin, Y. Kebal, S. Kondratyuk, Perspective constructions of tank-containers for transportation of light oil products, ammonia and hydrocarbon gases (in Russian), Journal "Rail transport Ukraine", 2, 44-46 (2012)

13. E. Lisowski, W. Czyzycki, Transport and storage of lng in container tanks, Journal of KONES Powertrain and Transport, 18(3), 193-201 (2011)

14. E. Lisowski, W. Czyżycki, K. Łazarczyk, Wdrożenie produkcji cystern kontenerowych do transportu i przechowywania gazów skroplonych, Biuletyn Instytutu Spawalnictwa w Gliwicach, 56(2), 25-31 (2012)

15. M. Ghiţă, C. Micu, M. Ţălu, Ş. Ţălu, 3D modeling of a shrink fitted concave ended cylindrical tank for automotive industry. Acta Technica Corviniensis: Bulletin of Engineering, 6(4), 87-92 (2013)

16. Wojciech czyżycki modeling of heat flow through multilayer internal supports of cryogenic vessels, Technical transportations, 2, 27-34 (2015)

17. J. Föhr, K. Karttunen, J. Enström, T. Johannesson, T. Ranta, Metal and composite intermodal containers in comparative cold tests with wood chips, Journal of Sustainable Bioenergy Systems, 5(1), 32-39 (2015)
18. O. Fomin, Increase of the freight wagons ideality degree and prognostication of their evolution stages, Scientific Bulletin of National Mining State University, 2, 68-76 (2015)

19. O. Fomin, Improvement of upper bundling of side wall of gondola cars of 12-9745 model, Metallurgical and Mining Industry, 1, 45-48 (2015).

20. A. Lovska, Simulation of loads on the carrying structure of an articulated flat car in combined transportation. International Journal of Engineering \& Technology, 7(4.3), 140-146 (2018)

21. O. Lovska, Investigation of the durability of the bearing structure of the tank-container placed on the carriage-platform during the maneuvering cooperation (in Ukrainian), Collection of scientific works of State University of Infrastructure and Technology, 28, 90-98 (2016)

22. Rules for the placement and fastening of goods in wagons and containers when transporting them by railways of the gauge of $1520 \mathrm{~mm}$ of the SMGS participating countries (in Russian). Part 1. General provisions. OSJD, 681 (2012)

23. Y. Krivovyazyuk, Estimating the equivalent loading of four-axle rail tank wagons with liquid cargo of different density for longitudinal impacts (in Russian), Tesis of PhD Dnepropetrovsk, 157 (1986)

24. Rules for the transport of dangerous goods, To the agreement on international railway cargo communication, 3, OSJD, 531 (2011)

25. V. Dyakonov, MATHCAD 8/2000: Special directory (in Russian), 592 (St. Petersburg, 2000)

26. D. Kiryanov, Mathcad 13 (in Russian), 608 (St. Petersburg, 2006).

27. A. Alyamovskiy, SolidWorks/COSMOSWorks 20062007. Engineering analysis by the finite element method (in Russian), 784 (Moscow, 2007). 